\title{
THE POTENTIAL FOR JOINT FARMING VENTURES IN IRISH AGRICULTURE: A SOCIOLOGICAL REVIEW
}

\author{
Peter Cush, Áine Macken-Walsh ${ }^{1}$
}

Received 10 December 2015; Accepted 18 March 2016

\begin{abstract}
Joint farming ventures (JFVs) are promoted within Irish and EU policy discourses as strategies that can enhance the economic and social sustainability of family farming. Research has shown that JFVs, including arrangements such as farm partnerships, contract rearing and share farming, can potentially enable farmers to work cooperatively to improve farm productivity, reduce working hours, facilitate succession, develop skills and improve relationships within the farm household. In the context of increasing policy promotion of JFVs, there is a need to make some attempt at understanding the macro socio-cultural disposition of family farming to cooperation. Reviewing sociological studies of agricultural cooperation and taking a specific focus on the Irish contextual backdrop, this paper draws the reader's attention to the importance of historical legacy, pragmatic economic and social concerns, communicative norms, inter-personal relationships, individualism and, policy and extension stimuli, all of which shape farmers' dispositions to cooperation and to JFVs specifically.
\end{abstract}

Keywords: Joint Farm Ventures, Cooperation, Irish agriculture, Resilience, Family Farming.

\section{Introduction}

Policy attention to the potential of cooperation in agriculture has experienced a revival in various parts of the world, with various forms of Joint Farming Ventures (JFVs) trumpeted as a survival strategy for farm households. It is argued that JFVs enable economic viability through enhanced knowledge and labour resources and/or scale; improved health and safety; and gender and youth equality (Chloupkova, Svendesen and Svendesen, 2003; Turner and Hambly, 2005; Almas, 2011; Macken-Walsh and Roche, 2012; European Parliament, 2014; Macken-Walsh and Byrne, 2015). Small cooperatives; farm partnerships; share farming; and contract rearing are examples of the types of JFVs promoted by various national and EU-level policy interventions and extension programmes. In Ireland, dairy farm partnerships are currently the prevalent type of JFVs. There are currently over 900 registered dairy farm partnerships and if the existing rate of annual uptake continues, Ireland will arrive at a scenario similar to Norway, where $25 \%$ of dairy farms operate in partnership (Egil-Flo 2006; Almas 2010). Given these trends and the high premium placed upon JFVs more generally within EU and Irish policy discourses, it is timely to consider the sociocultural disposition to cooperation amongst Irish farmers.

\footnotetext{
${ }^{1}$ Dr Peter Cush, Dr Áine Macken-Walsh, Teagasc Rural Economy and Development Programme (REDP), Athenry, Co. Galway, Ireland; Peter.Cush@teagasc.ie; Aine.MackenWalsh@teagasc.ie
} 
The literature has explored farmers' rationale for entering into various JFVs and the impacts of JFVs on the sustainability of family farming (Kirbak and Flø 2005; Almas, 2010; Macken-Walsh and Byrne, 2015). There is clear evidence that farmers consciously engage in JFVs to leverage the support of others in enhancing both individual and collective resilience. Farmers cite a myriad of reasons as to why they participate in JFVs including increased scale, the sharing of workloads, improved opportunities for developing new management strategies and business plans for the farm, and the sharing of skills and specialisations (Turner and Hambly, 2005; Macken-Walsh and Roche, 2012). Furthermore, research has indicated that JFVs have the capacity to deliver wide-ranging benefits such as improved equality in decision making among farm family members, reduced social isolation, increased leisure time and a reduction in psychological stress (Turner and Hambly, 2005; Egil-Flo 2006; Almas 2010; Macken-Walsh and Roche, 2012). JFVs also potentially provide a pathway for traditionally marginalised groups such as women and young people to have formalised roles in farm enterprises, necessary for the socio-cultural and relational sustainability of Irish agriculture (Macken-Walsh and Byrne, 2015).

While various policy instruments across the world systematically seek to support the establishment of JFVs, different economic, social and cultural conditions inevitably impact on how they take shape and operate in each agricultural context. Farmers can be differently disposed towards engagement in formalised JFVs, depending on the historical legacy of cooperation within their communities and their prior personal experiences. Yet, there is little commentary providing a synthesised appraisal of the cultural, social and economic dynamics that create positive conditions or otherwise for the establishment of JFVs.

This paper presents a critical review of sociological literature relevant to agricultural cooperation with reference to the Irish context. We explore how farmers' disposition towards cooperative behaviour hinges on critical variables located within the intersection of economic, social and cultural concerns. We begin this exploration by discussing the historical backdrop of cooperation in Irish agriculture, highlighting that despite certain cultural narratives that emphasis farm independence, there remains historical and contemporary cultural norms which favourably dispose farmers towards JFVs and formal cooperation. Second, we discuss farmers' economic motivations for cooperation with reference to the persistent economic viability problem experienced across much of Irish agriculture. Third and fourth we highlight the important role communication and inter-personal relationships play in farmers' perception of formal cooperation. Fifth we examine how individualism may impact upon the uptake of JFVs. Sixth we discuss some policy and extension initiatives to support farmers' contemplation and establishment of JFVs. Finally we offer a discussion and conclusion to the article where we consider the important policy implications arising from the paper.

\section{Cooperation in Rural Ireland: a historical backdrop}

Farmers' prior experiences of and adeptness at cooperation crucially impacts on their disposition towards JFVs and their chances of success (Ingram and Kirwan, 2011). Different traditions of cooperation invariably shape how social actors perceive JFVs and formal cooperation. Cooperation can have radically different connotations even within geographic regions. In the EU, for example, the legacy of enforced collectivisation in post-socialist states contrasts sharply with Irish smallholders' tradition of informal cooperation as a survival strategy.

Much of Ireland's cultural heritage is influenced by an enduring traumatic memory of the famine period and the poverty associated with British rule, which began in 1801 and ended in 1922, where a continual occurrence of dispossession, loss and defeat perpetuated among the Irish ancestry (McGoldrick, 1982; Kenny, 1985; Moane, 2002). It is argued that the years of colonial domination have left economic, political, social and cultural legacies that have been transmitted across generations and inform the contemporary cultural experience in Ireland (Kuhling and Keohane, 2007). While the political and economic subjugation that Ireland suffered as a result of British rule and colonisation have long since ended, psychosocial legacies remain and Moane (2014) argues that a continual level of internalised colonisation and oppression perpetuates within the Irish psyche. It is argued that the process of 'decolonisation' has yet to occur within the Irish discourse, where the history of trauma is critically reflected upon, processed and grieved through (Moane, 2002; Moane, 2014). Arguably, the collective memory of poverty, dispossession and 
economic vulnerability remains raw and emotionally unprocessed, perpetuating an internalised sense of fear, insecurity and helplessness within the Irish psyche (Moane, 2002). Such cultural narratives, which are often unconscious, are associated with a preoccupation with land ownership in Ireland and an associated pressure to maintain the lineage of family ownership through the intergenerational transfer of land (Hoppen, 1999).

A historically important transition occurred in the latter stages of the 19th century, which continues to inform much of the modern day agrarian identity (Kane, 2011). The land war ${ }^{2}$, which ran from 1879 until 1892, gave rise to conscientisation among tenants in relation to rights and entitlements to land, the injustice of tenancy and capital concentration in the hands of the occupying British landlords. This gave rise to the populist ideal of 'peasant proprietorship', where collective realisations emerged that farm households' security and status was dependent not only on farming the land but more crucially on owning it (Kane, 2011). Reinforced by collective narratives that emphasised economic vulnerability, fear and insecurity, an ideological shift occurred, with an increased desire amongst family farmers to own their land (Kane, 2011). An ideal farm type in Ireland emerged with the family at the heart of production and ownership (Jones 1995 cited in Kane, 2011; Foster 2014). Farming and land ownership acquired a symbolic presence in rural Ireland, representing security and independence.

The socio-cultural backdrop of Irish agriculture may lead to an assumption that there is considerable socio-cultural resistance to the idea of sharing the land and farm with an outside other, which is what JFVs involve. However, research in Ireland and across Europe has found evidence that runs contrary to this assumption. While individuals' private ownership of property is normatively perceived as a central characteristic of security and independence, expectations of solidarity are embedded in agricultural communities (O'Dowd, 1981; Curtin and Varley, 1991; Curtin, 1993; Byrne, Edmondson and Varley, 2001; Varley and Ó Cearbhaill, 2002; Sutherland and Burton, 2011; Cush and Varley, 2013; Macken-Walsh and Byrne, 2015). How land is farmed and how other communal challenges are addressed is marked by a distinctively cooperative approach. Varley and Ó Cearbhaill (2002) discuss the continuingly prominent collective voice of rural communities through voluntary agencies such as Muintir na Tíre, who seek to unite conflicting and diverging interests around the platform of pursuing the common good. Varley and Curtin (2006) have also shown that local development groups such as Forum in North Western Connemara offer a communitarian strand of development, underpinned by an egalitarian desire and a moral commitment to the centrality of community life. O'Dowd (1981), Curtin (1993), Curtin and Varley (1991) also show the strong cultural importance placed on cooperation as a resilience strategy in rural Ireland.

Furthermore, Arensberg and Kimball (1940) seminal study of family farming in Ireland in the 1930s highlighted inter-familial cooperation as crucial to the survival of the family farm. The 'cooring' system, originating from the Irish word cabhair meaning to help out or lend a hand to one's friend or neighbours (Byrne and O'Mahony, 2011), was a process where farm households would assist others during busy periods in the agricultural calendar such as harvest or turf cutting seasons (Arensberg and Kimball, 1940; Macken-Walsh and Byrne, 2015). Cooring, together with other customs of cooperation, were fundamental to the social organisation of rural society, not only as a mutual or charitable aid systems but as a social outlets for collective gatherings and festivities (O'Dowd, 1979). Patterns of cooperation between farms are noted to be continuingly strong and evolving to sustain Irish family farming (Varley and Curtin, 2006; Macken-Walsh and Roche, 2012; Macken-Walsh and Byrne, 2015). Despite entrenched socio-cultural narratives relating to trauma, colonisation and the Land War, wider cultural narratives of resilience that draw from the cooperative spirit, created conditions that are arguably accommodating of formalised cooperation through JFVs. Resilience strategies involving cooperation are commonly leveraged in response to diverse economic, social and cultural threats in Ireland (Macken-Walsh and Roche 2012; Macken-Walsh and Byrne, 2015) and such traditions provide a facilitative backdrop for farm families to engage in JFVs.

\footnotetext{
2 The land war represented an agrarian revolt against landlordism, and a search amongst small farmers and peasants for security through proprietorship, which also represented a symbolic protest against English Domination (see Kane 2011).
} 


\section{Economic and Social Rationality for Cooperation}

What further dispose the Irish farm family to the adoption of formal cooperation are the economic and social benefits of JFVs and the rational pragmatism present amongst the Irish farming community. Explaining cooperative behaviour through the lens of economic rationality has its roots in rational choice theory and methodological individualism (Forsyth and Johnson, 2014). From such perspectives, social and cultural phenomena are subjugated to economic incentives in understanding decision making. The incentive to cooperate is explained by a shortfall in personal material or monetary resources, requiring actors to seek the assistance of others in order to protect and pursue their economic interests (Popkin, 1979; Granovetter, 1992; Ostrom, 1998). Patterns of reciprocity become evident with actors investing in the welfare of others by sharing resources, predicated on the likelihood of return of commensurate benefits (Granovetter, 1992; Stone and Postdam, 1996). Actors are conceptualised as economically rational decision makers who "compare expected benefits and costs of action prior to adopting strategies for action" (Ostrom, 1991: 243). Through reciprocity, actors receive repeated benefits and are inculcated to the process of collective action, understood as of significant benefit and therefore worthy of continuance (Ostrom, Gardner and Walker, 1994). This perspective suggests that one's loyalty to reciprocity and cooperation are contingent upon increasing economic well-being (Granovetter, 1992).

An immense literature has accumulated on cooperative behaviour in agriculture, which is noted as a critical feature of the reproduction of small scale family farming (Wolf, 1966; Kerblay, 1971; Popkin, 1979; Levin, 1988). Much of this debate is informed by Chayanov's $(1925,1986)$ discussion of peasant rationality, where the survival of the family farm is improved by the deployment of household labour and family members' willingness to self-exploit their labour for the benefit of the household. Chayanov drew our attention to the importance of collective efforts between members of the farm household, without which it would be impossible to survive. Wolf (1996) also noted a similar pattern and extended the argument, showing, however, that under certain circumstances the deployment of collective family farm labour was not sufficient to meet requirements. In such situations, family farms were required to extend cooperation beyond the unit of the household and forge linkages with other households in periods of economic duress (Wolf, 1966). In Wolf's study, peasants would share resources and labour in order to boost survival chances. Similarly, Samuel Popkin's study of the peasantry illuminated a similar pattern, describing peasants as economically rational problem solvers, who could safeguard their own interests by bargaining with others to achieve mutually accepted outcomes (Popkin, 1979).

Irish farm households strategically use interfamilial cooperation to increase their individual survival chances, leveraging support from both within the family and wider communal networks, to achieve productivist goals of enhanced scaled and productivity and to satisfy labour requirements (Macken-Walsh and Byrne, 2015). Furthermore, traditional patterns of resilience, described by Macken-Walsh and Byrne (2015) who cite Arensberg and Kimball's (1940) study of small farm society in Ireland, highlight the instrumental reasoning behind cooperation.

Systems of cooring, which were partnerships of different farmers, constituted an "instrumental resilience strategy propagated collectively by members of the farming community" (MackenWalsh and Byrne, 2015: 6). Families invested time and resources strategically to support other farm families on a reciprocal basis, which helped support the farm household. In addition cooring also reflected the recognition amongst farm families of the need for social sustainability and the reproduction of small farm society. Farm households used a pattern of sequencing that prioritised 'viable' farm families, "where viable farm families were those that had succeeded in producing multiple offspring" (Macken-Walsh and Byrne, 2015: 7). The most marginal in this sequencing pattern were the childless and single women beyond reproductive age, who could neither provide a supply of labour nor facilitate the process of succession to the next generation. This process highlights the historical pattern of instrumental cooperation within Irish farm households, which rests on a strong desire amongst farm households to reproduce the family farm and sustain the wider farm society on which they were dependent. Such rational pragmatism continues to this day, as farmers repeatedly prioritise the financial stability of the family farm and often negotiate significant challenges to ensure the farm family survives (McDonald et. al. 2014). 
The rational pragmatism of Irish farmers arguably disposes them favourably to JFVs given the range of associated social and economic benefits, with these proving particularly important considering the many challenges facing family farming. Contemporary Irish agriculture is characterised by low profitability and the generating of income for the farm household is often undertaken by the farm spouse through her off-farm work (Shortall 2014). Farm incomes averaged €26,974 in 2014 (Hennessy and Moran 2014a) and only 37\% of Irish farms are defined as economically viable (Hennessy and Moran 2014b). The farm viability problem is typically explained by farms having inadequate scale and efficiencies to produce commodities in a world market. Another explanation is that farms do not differentiate their products sufficiently in the marketplace, which would allow them to command a higher price and relieve them of the pressure to produce more volume (Macken-Walsh, 2010). JFVs have been identified as a model to facilitate both routes towards farm viability, by facilitating farmers to join their farms together to achieve more scale and efficiencies and/or to introduce new skills and specialisms to farm enterprises with a view to differentiating farm produce (Hennessy et. al. 2009).

In addition, inadequate labour is a common threat to the survival of family farms, particularly where the land holder is responsible for the sole running of the farm. Kirbak \& Flø (2005) coined this as the 'one man farm' phenomenon, and is widely recognised to be economically unsustainable as too much stress is placed on the farmer and there is not enough labour to complete farm tasks. JVFs enable farmers to pool labour, skills and resources together to enhance the productive capacity of the farm and reduce the 'one man farm' problem (Kirbak \& Flø 2005; Almas 2010). In addition, 'the one man farm' phenomenon has tended to push young adult family members away from the farm, who seek financial independence and are reluctant to operate in a period of 'protracted boyhood'(Arensberg and Kimball 1940), where they provide mainly manual tasks on the farm without contributing to decision making. JFVs can resolve this tension by providing a function for young and older farmers to work together, enabling young farmers to gain decision making functions on the farm (Macken-Walsh and Roche 2012). Here young farmers can bring critical skills and competencies to the farm, particularly higher levels of formalised training with $13.4 \%$ and $27 \%$ of farmers under the age of 35 obtaining a third level qualification and a certificate in farming or a farm apprenticeship respectively (CSO 2012). By contrast, only $3.3 \%$ of farmers aged $55-64$ obtained a third level qualification, while $5.2 \%$ had received a certificate in agriculture or a farm apprenticeship.

Furthermore JFVs between neighbouring farmers reduce farming work hours and enable farmers to share households tasks such as childrearing, freeing up women's time to work off-farm (Macken-Walsh 2010 Egil- Flø 2006), which contributes to more equitable relationships within the farm family home (Byrne et. al. 2014). Changing rural masculinities, which increasingly place a higher priority on interpersonal relationships, the needs of other family members and increased work/life balance (Macken-Walsh and Byrne 2015) mean that more equitable social relationships are increasingly valued within the farm family. JFVs capacity to deliver these benefits appeal to the rational pragmatism of family farmers and a considerable opportunity presents itself if farmers become more acutely aware of such benefits.

What further enhances farmers' willingness to engage in JFVs is that they involve a small number of participants, usually two or three farmers and therefore can more easily avoid the financial and free rider problems that can plague larger cooperatives and producer organisations. The potential for free riding is also tempered by the on-farm agreements that typically accompany arrangements such as farm partnerships, share farming and contract rearing ${ }^{3}$.

\section{Communicative norms}

Of course, it is not just the rational pragmatism of farmers that propels them towards cooperation. The literature has discussed at length how, actors' capacity for cooperation is greatly improved through communication (Ostrom, Gardner and Walker, 1994; Ostrom 2010). While farmers often

\footnotetext{
${ }^{3}$ Each participant is bound by a legal contract which clearly specifies their roles and channels of mediation, conciliation and arbitration that should be followed in the case of a dispute. In cases where free-rider behaviour does arise, there is usually a referee nominated in the formal agreement, who has the role of addressing and mediating problems arising in the JFV (Teagasc 2016a, b and c).
} 
have a strong economic, social and cultural basis for cooperation, obstacles emerge where poor communication exists between the parties involved (Ingram and Kirwan, 2011). Indeed it is often a lack of communication which prevents farmers from overcoming the mistrust, anxiety and uncertainty that can attend the changes associated with formal cooperation (Ingram and Kirwan, 2011; Macken-Walsh and Roche, 2012). A useful theoretical and analytical basis for communication is provided by Habermas (1984), who theorises that necessary forms of consensus for successful cooperation are dependent on a strong commitment, by all parties, to processes of communication. He argues that language is an enabler of communication between actors' inner worlds to the 'other'. For successful communication, the speaker must also occupy the position of 'hearer' and both parties must collectively engage in a process of constructive argumentation. Through such processes, an 'intersubjective exchange' leads to consensus or "an affirmative position" engaging all parties (Habermas, 1984: 95-97).

Communication is also a process that enables people to subtly observe others and subjectively evaluate others' inherent level of trustworthiness. Actors are aware that human relationships carry an element of risk, and that there is a significant discrepancy between how people present themselves and how they actually behave in reality (Ostrom, Gardner and Walker, 1994). Actors' decisions to cooperate can be often based on intuition, which is often built over time. Through close and regularised contact, where actors can communicate subconsciously and get a sense of each other, the capacity for trust and cooperation can be improved or otherwise. Successful communication enhances the 'consensual power' of decision-making (Haugaard, 1997) and serves to reduce the level of uncertainty surrounding the behaviour of others (Janssen and Ostrom, 2008). The emotional weight farmers attach to their own individualised farming practices arises as a crucial issue where JFVs are concerned, because the latter can involve farmers who have entirely different practices and belief systems (Ingram and Kirwan, 2011; Macken-Walsh and Roche, 2012). Such JFVs, arguably, are best avoided (Ingram and Kirwan, 2011; MackenWalsh and Roche, 2012). However, effective communication has the capacity to enhance trust and reduce anxiety even in JFVs between farmers who have compatible practices, beliefs and goals.

A favourable characteristic of Irish agriculture is the high cultural premium placed on communication. Communication, colloquially referred to as "chatting", has long served to promote intimate social relationships among farmers and to provide a network for the diffusion of important information on farming matters (Frawley, 1993 citing Breathnach, 2000; Breathnach, 2000). The local pub in particular provides what Oldenburg (1999) has referred to as "a third place", a meeting point for local farmers where they can discuss issues of common concern, trade insights and share a collective ethic of mutuality and interdependence (Arensberg and Kimball, 1940; Rosenzweig, 1991; Kearns, 1996 Breathnach, 2000; Share, 2003). Such "chatting" is embedded in the heart of social relations in rural Ireland and is often buttressed by other important "third places", such as the local church and the mart. The impulse to converse in rural Ireland is often unconscious and exists as a form of practical consciousness, which fosters social connectedness (Gallagher, 2012). Such normative elements to social life are critical to the establishment of formally organised cooperative agreements in Ireland (Cush, 2012; Cush and Varley, 2013) and provide a facilitative platform for the adoption of JFVs.

\section{Inter-personal relationships}

In agricultural communities where farm families have often farmed alongside each other for generations, familiar social bonds exist that can impact on cooperation. Where actors have positive experiences of cooperation, it is more likely they will view cooperation as beneficial to their interests. Individuals have a remarkable capacity to store memories of important interactions and to use these in order to predict the likely course and outcomes of similar interactions in the future (Granovetter, 1992). Thus, having a positive experience with someone helps to reassure individuals that this person is reasonable and can be relied upon in the future. Individuals are said to develop positive heuristics towards these individuals and through repeated interactions can construct conventions, or social norms, that normalise trust and make acts of deviation unthinkable (Granovetter, 1992). 
Having positive experiences of cooperation also gives people a sense of connection to the world around them. Engaging positively in a collective experience with other people affords individuals a sense of interpersonal fulfilment, providing a richness to their lives and enabling them to gain a deep understanding of who they are (Durkheim, 1951). Individuals positively associate with these experiences and are thus more likely to be trusting of these relationships and to seek them out in the future, even in cases where it is not perfectly rational for them to do so (Granovetter, 1985). Consequently, positive social relationships provide a facilitative platform from which cooperation can emerge.

Conversely, a history of poor social relationships are detrimental to the process of cooperation, which tends to be perceived as damaging to one's interests and as a result (Granovetter, 1992; Curtin, 1993) even where economic benefits are clear, we should not assume that farmers will view cooperation as positive (Baumeister et al, 2001; Nass and Yen, 2010) As Granovetter (1992: 34) highlights, "even when one has not had dealings with a certain person for many years, a reactivation of the relationship does not start from scratch but from some set of previously attained common understandings and feelings". The past, thus, clearly informs the present and where disputes have arisen, a challenging platform for cooperation is set. With a history of poor social relationships, people are less able to build feelings of trust and may consequently view cooperation as inimical to their best interests.

Harmonious social relations in rural Ireland may not be assumed. While a normative tradition of communal solidarity and mutuality is represented in the literature on family farming, such descriptions tend to be overly romantic and neat by way of explanation, reifying social life in rural Ireland (Curtin, 1988). Discord and conflict are commonplace and have a proven capacity to undermine cooperative behaviour in rural Ireland (Curtin, 1988; Curtin, 1993; Phyne, 1999; Cush, 2012). There is, however, evidence that positive social relationships also exist, which buttress the process of collective action and enable rural actors to draw upon trust which facilitates cooperation. Cush and Varley (2013) show how normative trust and reciprocity support formal and informal cooperative behaviour in Irish aquaculture. Curtin (1993) also highlights the critical role positive social relationships have played in sustaining cooperation as a form of economic organisation in the west of Ireland. Taylor (1987) furthermore illustrates how a history of positive social relationships enabled a group of Donegal inshore fishermen to develop a complex system of cooperation, which sustained not only the local fishery but also the socio-cultural and normative framework upon which they were dependent for a distinct and rooted self-hood at the individual level.

With regard to the family farming unit, we also see favourable relationships supporting the formation of JFVs both within and outside of the family. Family farm members remain committed to supporting the resilience of the family farm even where they might be excluded and we this clearly amongst non-successor farm offspring (Cassidy and McGrath, 2014). Cassidy and McGrath (2014) note the nuances of succession, showing that it is a highly complex process which involves cooperative buy-in from the future heir, the parents and the disinherited siblings. Among the siblings we see a deep attachment to the farm as an enduring place in their lives, and they retain a desire to maintain the farm within the hands of the family. Non-successor offspring remain committed to supporting the succession process, as the farm remains intimately connected to their self-identity. In this context, siblings will support JFVs should they understand that they contribute to the resilience of the family farm.

\section{Individualism}

What has also arguably shaped the cultural perception of cooperation is the socio-cultural shift that has occurred in Ireland in the last two decades. During the 1990s and 2000s, Ireland embarked upon a self-styled economic miracle, commonly referred to as 'the Celtic Tiger', where rational economic self-interest increasingly informed social relations, trumping virtues of social solidarity and collective interest in the process (Fagan, 2002; Kirby, 2005). The Celtic Tiger allowed Ireland to project a modern, liberal and progressive image, which was founded on the ideological principles of individualism, quite typical of advanced capitalist societies (Kirby, Cronin and Gibbons, 2002; Kirby, 2005). New constructions of 'Irishness' began to dominate the popular conscience, with cultural identity increasingly framed by capitalist ideology and 
market-based philosophy (Kirby, Cronin and Gibbons, 2002). Traditional values of the 'small man' were now mixed with contemporary notions of 'high earners' and 'entrepreneurs' (Fagan, 2002). Increasingly, Irish people were defined by mass consumption and a culture of individualism (Corcoran, 2007).

However, the extent to which such trends observed at the national level resonated with rural communities is less apparent. Multiple studies have indicated that even the most commercialoriented farmers in Ireland tend to be wedded to the family farming ethos and are, thus, reluctant to compromise social and cultural capital for the sake of economic gain. For instance the sale of farmland did not increase during the 'Celtic Tiger' period despite the prevalence of individualistic principles in Ireland. The rate of less than 1\% of farmland transferred on the open market annually (Hennessy, 2006) continued during the Celtic Tiger boom, indicating the continued socio-cultural importance of farmland despite its soaring economic valuation in the market. Moreover, Cush and Varley (2013: 16) show that "despite the rise of forces that favour egoistic individualism in Celtic Tiger Ireland" we do not see cooperation demise as a resilience strategy in rural Ireland.

However, it is arguably the case that cooperation is challenged in contemporary times by individualistic principles, which is highly indicative of social relations under advanced capitalist regimes (Putman, 2000). The consequences of this for agriculture are quite clearly expounded by Emery (2015), who, referring to the UK context, illustrates how capitalist ideology tends to convince farmers that their survival, freedom and independence is achieved through individualism, with neighbouring farmers increasingly viewed as natural competitors. Emery, (2015) discusses how cooperative patterns of resilience in agriculture tend to become mystified under capitalist ideology and viewed with a sense of suspicion and mistrust.

Irrespective of broadly occurring transformation towards or indeed resistance to individualistic tendencies under capitalist regimes, it has always been the case that Irish agriculture facilitates individualism to a degree. Individual resilience - of the male farm owner or patriarch specificallyhas been a notable characteristic of family farming. This is illustrated quite clearly in the sense of prestige associated with maintaining farm individuality and privacy (Kennedy, 1991; Crowley, 2006; Macken-Walsh, 2009; Cassidy and McGrath, 2014). The esteem associated with independence is underpinned by strong patriarchal relations within Irish farm households, where male identity is informed by a pronounced sense of duty, responsibility and ownership (Shortall, 1997; Shortall, 2014). The cultural desire for farm independence and the increasing tendency for egoistic individualism in the context of post Celtic-Tiger Ireland arguably pose a threat to the adoption of formal cooperation and JFVs.

However, presenting an increasing and considerable challenge to farmer's identity is the difficulty in generating an income from the farm (Shortall 2014). This poses a significant challenge to the male farmers' identity, as they can no longer maintain occupational supports for the continuance of their breadwinner, masculine role, giving rise "to feelings of guilt, stress and anxiety" (Ní Laoire 2005: 105). In addition, in the context of increasing rural restructuring and the diversification of the local economy, the prestige vested in agriculture has declined, and increasingly off-farm professional work is valued and esteemed within rural Ireland (Ní Laoire 2005). This is particularly true for the younger members of the Irish farm family, who associate farming with long working hours and a difficulty to maintain incomes, with farming in this context seen something of a 'poisoned chalice' (Kelly and Shortall 2002). It can no longer be assumed that young farmers will take over the farm and many seek alternative lifestyle choices with a better standard of living (Macken-Walsh and Byrne 2015). In many instances young farmers pursue their individual interests and increasingly question and challenge socio-cultural norms which pressurise them to take over the farm.

JFVs capacity to improve the economic viability of the family farm (Hennessy et. al 2009) means that they provide male farmers' with the most realistic means to support traditional masculine roles. Individualised routes are increasingly challenged in the context of declining farm incomes and formal cooperation provides considerable scope for the empowerment of the male farmer. In addition, by freeing up working hours, farmers can pursue certain off-farm interests as they increasingly enjoy a more nuanced lifestyle (Macken-Walsh 2010). Furthermore, JFVs enable farmers to combine different skills and specialisms, and construct an enterprise out of the farm 
which can enable career goals and aspirations to be fulfilled on farm. Moreover, JFVs provide a structure where the standard of living can be an increased for farmers as the burden of the 'one man farm' is reduced, working hours improve and holidays become a more frequent possibility (Macken-Walsh 2010; Almas 2010). In the context of shifting rural masculinities, where an increased priority is placed upon family time and a flexible attitude towards work (Bye 2009), the allure of JFVs is significantly enhanced (Almas 2010; Macken-Walsh and Byrne 2015). Undoubtedly new cultural constructions of individualism present challenges to cooperation, however JFVs provide a structure capable of resolving this tension by enabling farm members to fulfil individual expectations and desires.

\section{Policy and Extension Support of JFVs}

From the above we see that the socio-cultural landscape of Irish agriculture is well disposed towards the adoption of JFVs but support from policy and extension services is required (MackenWalsh and Roche 2012). Internationally, JFVs are promoted by novel extension programmes. For instance in Cornwall in the UK, the Fresh Start Initiative (FS) was launched in 2004 by the Commission for the future of Farming and Food in the UK, funded by the European Agricultural Fund for Rural Development (EAFRD). The idea behind the initiative was to increase the participation of young farmers to agriculture by setting up farm partnerships with older farmers who were looking to take a step back from farming and semi-retire. FS launched a matchmaking service where young, aspiring farmers were matched with older farmers looking to take a step back but had no identified successor. FS brought the two interested parties together and helped them to draw up a partnership plan which would suit both of their needs and requirements. In addition, follow-up advisory and mentoring programmes were offered to the participants in order to assist in any difficulties or obstacles faced (Ingram and Kirwan 2011).

At EU level, EAFRD funds a dedicated policy measure to encourage cooperation in agriculture, which includes JFVs. The possibilities of this measure are explored by Macken-Walsh and Brosnan (2012). They note that of critical importance is that supports and extension services for farmers are delivered in way that enable them to contemplate JFVs in an informed manner so they can customise arrangements to suits their own individual circumstances. In Ireland, extension supports targeted at JFVs are offered by Teagasc, Ireland's Agriculture and Food Authority, and farmer interest groups such as Macra Na Feírme. However, recent nationally representative survey data indicate that many farmers are not aware of the potential benefits associated with JFVs, and a significant effort will be required to show demonstrative evidence of the benefits of formal collaboration over and above informal cooperation (Macken-Walsh et al., 2015). In a recent survey conducted by Teagasc, on a scale of -2 to +2 , only -0.72 farmers had even contemplated setting up a JFV (Macken-Walsh et al. 2015). Policy makers must be cognisant of farmer's rationalities and dispositions towards cooperation and provide information which clearly and practically illustrates how JFVs operate and the potential benefits. While this is so, it is crucial that the supports are not paternalistic and farmers must have a sense of ownership of the learning processes (Macken-Walsh and Roche 2012). An extension approach that fosters conversations to be opened up about farm partnerships is warranted and one way this can be achieved is through the discussion group network operating in Ireland. The discussion groups that are in operation nationwide offer a platform for social learning and knowledge transfer between farmers and essentially attempt to relate to and transform existing norms. They provide a significant opportunity for policy makers to enable communicative processes between farmers with a view to enhancing their capacity for cooperation (Macken Walsh and Roche, 2012). Significant attempts should thus be made to target such discussion groups as incubators for JFVs, an extension methodology for which is set out by Macken-Walsh and Roche (2012). Utilising existing networks within and surrounding discussion groups stands to support emerging JFVs (Ingram and Kirwan, 2011).

More pragmatic concerns relate to the bureaucracy and costs involved in establishing a JFV. In Ireland, establishing a JFV can be a lengthy and complicated process, which involves the input of solicitors, accountants and agricultural advisors which can be expensive. These costs are a considerable barrier for Irish farmers who are on low incomes, averaging €26,974 per annum (Hennessy and Moran 2014a). However, new supports offered through the EAFRD, will offset at 
least some of these establishment costs. Farmers may also engage a facilitator to assist them to establish a JFV, supported by the EAFRD. Currently, there are few professional actors that have expertise in facilitating and overseeing the development of a sufficiently detailed comprehensive agreement to underpin successful JFVs. Such agreements are required in order to realise the benefits of JFVs and to mediate between and protect parties in the case of disputes. Furthermore, facilitators can take the role of liaising on farmers' behalves with banks, solicitors and accountants. With the availability of support through the EAFRD henceforth, it is possible that the rate of establishment of JFVs will increase and that a greater number of professionals will acquire expertise in facilitating farmers' establishment of JFVs. However, there are financial disincentives in the Irish context that restrict farmers' eligibility for and payments from various policy and subsidy schemes when they are parties to JFVs. Such disincentives must be eliminated, where possible, to effectively encourage farmers' uptake of JFVs.

\section{Conclusion and discussion}

The factors which shape collective behaviour have been described as a "spaghetti plate" of variables (Ostrom, 2010). By no means do we suggest that a definitive and exhaustive account is provided in this paper of the diverse and intersectional factors which dispose Irish farmers to cooperation. However the broad categories of macro level factors outlined above provide a foundation from which we can begin to examine how and why farmers are disposed in particular ways towards cooperation.

Ireland's colonial past, its traumatic history of famine and poverty and its rather dramatic arrival as an advanced capital state inevitably informs farmers willingness or otherwise to cooperate. The historical memory of dispossession and defeat by the colonising force of British occupation remains embedded within the Irish rural psyche, and there continues an attachment to land ownership and farm independence. Nonetheless, a strong historical legacy of cooperation amongst farmers in rural Ireland through systems such as cooring, and patterns of cooperation that are continually evolving amongst Irish family farmers (Macken-Walsh and Byrne 2015) dispose Irish farmers positively to the prospect of formal cooperation and JFVs.

More critically, the rational pragmatism of Irish farmers provides significant scope for the embracing of JFVs amongst the general population of family farmers. JFVs have the capacity to deliver a range of economic, social and cultural benefits, such as increased production scale, increased labour, diversification of the farm enterprise, increased leisure time, better opportunities for young farmers and improved relationships within the family home. Should farmers become more cognisant of these benefits, a more widespread recognition of JFVs as a resilience strategy is likely to occur. Leveraging farmers' capacity for discursive practice is crucial in achieving this, reducing uncertainties and anxieties and enabling them to build consensual power around formal cooperation. The 'chatting' culture, a social norm in rural Ireland, provides an important platform for intersubjective exchange amongst farmers and its potential role for stimulating communicative processes around cooperative farming should not be discounted.

What can harness discursive processes further are positive social relationships amongst the general farming population. While a harmonious set of social relationships within Ireland's rural population cannot be assumed (Curtin 1988), positive social relationships and affective ties do form a significant feature of rural Irish society, and they have a proven capacity to enhance the adoption of formal cooperation in Ireland (Cush and Varley 2013).

Added to this are debates around individualism, and whether the emergent culture of individualism presents a barrier to the perception and likely adoption of formal cooperation. While it is not easy to accurately assess this, from prior evidence we can ascertain that JFVs enable family farmers to pursue individualised preferences on- and off-farm while also enhancing the resilience of the family farm through reconstituted relationships that foster the collective as well as the individual. Rather than presenting a barrier to the adoption of JFVs as suggested by Emery (2015), perhaps the increasing desire for satisfying individual needs will make JFVs and formal cooperation more appealing.

Critical for the increased uptake of JFVs is increased support from policy and extension services to help farmers deal with the practical demands of setting up JFVs. New facilitation supports to 
assist in farmers' establishment of JFVs is welcomed by farmer interest groups but financial disincentives as a result of scheme restrictions must be eliminated where possible. Policy initiatives may also support the opening up of communicative processes within the agricultural community using the existing network of discussion groups or dedicated groups. Such an initiative could make a purposeful contribution to conscientisation among farmers of the "array of imaginable possibilities" (Emery, 2015: 60) attainable through JFVs.

Perhaps, it is state support, through extension and policy services which is consequently the most critical of all variables discussed. Cultural barriers to formal cooperation remain in place to some degree. In theory, the ideology of individualism as propelled by late modern society provides a socio-cultural barrier. In addition, the cultural desire for farm independence can restrict farmers' willingness for cooperation with an outside other. However there are significant socio-cultural norms in Ireland which enhance the adoption of JFVs and the state must build upon the sociocultural factors which facilitate cooperation. While economic incentives, information on the practical benefits of JFVs and legal and accountancy advice are all worthwhile, what is perhaps even more crucial is for policy makers to act as visionaries and to build awareness of the cultural value of cooperation, drawing on the positive cultural narratives around collective action in rural Ireland. Rather than a primary focus on technical matters, the discussion groups facilitated by Teagasc offer a unique opportunity to enable discursive practices around cooperation; what farmers consider its place, value and role to be in rural Ireland and in doing so provide an alternative set of ideological resources that challenge the resistance posed by the ideology of individualism and traditional resilience strategies which stressed the importance of farm independence. Moreover, this would provide family farmers with a greater sense of ownership of JFVs in Ireland, how they emerge, develop and forms they take. This all hinges crucially on state support, and its willingness to provide the time, energy and resources to properly facilitate JFVs in Ireland.

\section{Acknowledgements}

This work was funded by the Department of Agriculture, Food and the Marine, Ireland under the Research Stimulus Fund (RSF), Project Number: 11/S/151.

References

[1] Almas, A. (2010). I have seen the future and it works! How Joint Farming may solve contradictions between technological level and farm structure in Norwegian dairy production. In Bonanno, A., Bakker, H., Jussaume, R., Kawamura, Y. \& Shucksmith, M., eds., From Community to Consumption: New and Classical themes in Rural Sociological Research (pp. 3-16). Bingley: Emerald Group Publishing.

[2] Arensberg, C. \& Kimball, S. (1940). Family and Community in Ireland (Third Edition), Ennis: CLASP.

[3] Baumeister, R., Bratslavsky, E., Finkenauer, C. \& Vohs K. (2001). Bad is stronger than good. Review of General Psychology 5(4): 323-370. DOI: 10.1037/1089-2680.5.4.323.

[4] Bowen, S. \& De Master, K. (2014). New farmers' efforts to create a sense of place in rural communities: insights from southern Ontario, Canada. Agriculture and Human Values 31(4): 549-562. DOI: 10.1007/s10460-014-9489-3.

[5] Breathnach, P. (2000). The Evolution of the spatial structure of the Irish dairy processing industry. Irish Geography 33(2): 166-184. DOI: 10.1080/00750770009478589.

[6] Bye, L. M. (2009). 'How to be a rural man': young men's performances and negotiations of rural masculinities. Journal of Rural Studies 25(3): pp. 278-288. DOI: 10.1016/j.jrurstud.2009.03.002.

[7] Byrne, A., Edmondson, R. \& Varley, T. (2001). Arensberg and Kimball and Anthropological Research in Ireland: Introduction to the Third Edition, Conrad Arensberg and Solon Kimball, Family and Community in Ireland. Ennis: CLASP. 
[8] Byrne, A., \& O'Mahony, D. (2011). Family and Community: (Re)Telling Our Own Story. Journal of Family Issues, 33(1): 52-75. DOI: 10.1177/0192513X11421121.

[9] Cassidy, A. \& McGrath, B. (2014). The Relationship between 'Non-successor' Farm Offspring and the Continuity of the Irish Family Farm. Sociologia Ruralis 54(4): 399-416. DOI: 10.1111/soru.12054.

[10] Chayanov, A. V. (1925). The theory of the Peasant Economy (1986 edition). Madison: University of Wisconsin Press.

[11] Chloupkova, J., Svendesen, G. L. H. \& Svendesen, G. T. (2003). Building and destroying social capital: The case of cooperative movements in Denmark and Poland. Agriculture and Human Values 20(3): 241-252. DOI: 10.1023/A:1026141807305.

[12] Corcoran, M. (2007). Consumption and identity. Field day Review 3: 239-245.

[13] Crowley, E. (2006). Land Matters: Power Struggles in Rural Ireland. Dublin: Lilliput Press.

[14] CSO (2012). Census of Agriculture 2010: Final Results. Cork: Central Statistics Office.

[15] Curtin, C. (1986). The Peasant Family Farm and Commoditization in the West of Ireland (pp. 58-76). In: Long, N., Van der Ploeg, J. D., Curtin, C. \& Box, L., eds., The Commoditization Debate: Labour Process, Strategy and Social Network. Papers of the Department of Sociology 17, Wageningen: Agricultural University Wageningen.

[16] Curtin, C. (1988). Social Order, Interpersonal Relations and Disputes in a West of Ireland Community (pp. 76-91). In: Tomilson, M., Varley T. \& McCullagh, C., eds., Whose Law and Order? Aspects of crime and social control in Irish society. Belfast: Sociological Association of Ireland.

[17] Curtin, C. \& Varley, T. (1991). Populism and Petit Capitalism in Rural Ireland. (pp. 97-119). In Whatmore, S., Lowe, P. \& Marsden, T., eds., Rural Enterprise: Shifting Perspectives on Small-scale Production, London: David Fulton.

[18] Curtin, C. (1993). Another Commons Tragedy? Shellfish Cooperatives in North West Connemara. [Paper to Circle for European Studies]. Assisi.

[19] Cush, P. (2012). The Rise and Fall of Cooperative Resource Management: The Case of Killary Harbour. [Unpublished Doctoral Thesis]. Galway: National University of Ireland.

[20] Cush, P., \& Varley, T. (2013). Cooperation as a survival strategy amongst West of Ireland Small Scale Mussel Farmers. Maritime Studies 12(11). DOI: 10.1186/2212-9790-12-11.

[21] Department of Agriculture, Food and the Marine, Ireland (2011). Farm Partnership Reference Paper. Dublin: Department of Agriculture, Food and the Marine.

[22] Department of Agriculture, Food and the Marine (2013). 2015 National Reserve and Young Farmers Scheme: Terms and Conditions. Available at: https://www.agriculture.gov.ie/media/migration/farmingschemesandpayments/capentitleme ntsrelatedapplicationforms/nationalreserveandyoungfarmersschemes/NatResYFSrevTC06 0315.pdf Accessed 19/02/16.

[23] Durkheim, E. (1951). Suicide. New York: Free Press.

[24] Echterhoff, G. (2012). Shared-Reality Theory (pp. 180-200). In: Van Lange, P., Kruglanski, A. \& Higgins, E., eds., The Handbook of Theories of Social Psychology Volume 2. London: Sage Publications.

[25] Egil-Flø, B. (2006). Joint farmers - who are they and why do they go into joint farming? Duniden Agrifood Conference.

[26] Emery, S. B. (2015). Independence and Individualism: conflated values in farmer cooperation. Agriculture and Human Values 32(1): 47-61. DOI: 10.1007/s10460-014-9520-8.

[27] European Parliament, (2014). Family Farming in Europe: Challenges and Prospects: Indepth Analysis. Retrieved from: 
http://www.europarl.europa.eu/RegData/etudes/note/join/2014/529047/IPOLAGRI_NT(2014)529047_EN.pdf.

[28] Fagan, G. (2002). Globalisation and Culture: Placing Ireland. Annals of the American Academy of Political and Social Science 581: 133-143. DOI: 10.1177/000271620258100112.

[29] Forsyth, T. \& Johnson, C. (2014). Elinor Ostrom's Legacy: Governing the Commons and the Rational Choice Theory Controversy. Development and Change 45(5): 1093-1110. DOI: 10.1111/dech.12110.

[30] Foster, R. (2014). Vivid Faces: The Revolutionary Generation in Ireland: 1890-1923. London: Penguin Books.

[31] Gallagher, C. (2012). Connectedness in the lives of older people in Ireland. Irish Journal of Sociology, 20(1): 84-102. DOI: 10.7227/IJS.20.1.5.

[32] Garrido, S. (2007). Why Did Most Cooperatives Fail? Spanish Agricultural Cooperation in the Early Twentieth Century. Rural History 18(2): 183-200. DOI: $10.1017 /$ S0956793307002142.

[33] Granovetter, E. (1985). Economic Action and Social Structure: The Problem of Embeddedness. American Journal of Sociology, 91(3): 481-510. DOI: 10.1086/228311.

[34] Granovetter, E. (1992). Problems of Explanation in Economic Sociology (pp. 25-56). In Nohria, N. \& Eccles, R., eds., Networks and Organisations. Boston: Harvard Business School Press.

[35] Habermas, J. (1984). Reason and the Rationalization of Society: Volume 1 of The Theory of Communicative Action, English translation by Thomas McCarthy. Boston, Beacon Press

[36] Habermas, J. (1987). Lifeworld and System: A Critique of Functionalist Reason, Volume 2 of The Theory of Communicative Action, English translation by Thomas McCarthy. Boston: Beacon Press.

[37] Haugaard, M., (1997). The consensual basis of conflictual power: a critical response to "using power, fighting power" by Jane Mansbridge. Constellations 3(3): 401-406. DOI: 10.1111/j.1467-8675.1997.tb00067.x.

[38] Hennessy, T. (2006). The agricultural land market: Situation and outlook. The Property Valuer (Summer Edition): 20-21.

[39] Hennessy, T., Kinsella, A., O'Donoghue, C. \& Thorne, F. (2009). The Economic Benefits of Working Together. Teagasc Conference on Joint Farming Ventures.

[40] Hennessy, T. \& Moran, B. (2014a). The viability of the Irish farming sector in 2014. Dublin, Teagasc.

[41] Hennessy, T. \& Moran, B. (2014b). The National Farm Survey. Dublin, Teagasc.

[42] Hoppen, K. (1999). Ireland since 1800: conflict and conformity, $2^{\text {nd }}$ ed., London: Longman.

[43] Ingram, J. \& Kirwan, J. (2011). Matching new entrants and retiring farmers through joint farm ventures: Insight from the Fresh Start Initiative in Cornwall, UK. Land Use Policy 28(4): 917927. DOI: 10.1016/j.landusepol.2011.04.001.

[44] Janssen, M. \& Ostrom, E. (2008). Turfs in the Lab: Institutional Innovation in Real-Time Dynamic Spatial Commons. Rationality and Society 20(4): 371-397. DOI: $10.1177 / 1043463108096786$.

[45] Kane, A., (2011). Constructing Irish National Identity: Discourse and Ritual during the Land War, 1879-1882. New York: Palgrave.

[46] Kelly, R. \& Shortall, S. (2002). Farmers Wives: Women who are off-farm breadwinners \& the implications for on-farm gender relations. Journal of Sociology 38(4): 327-343. DOI: $10.1177 / 144078302128756714$. 
[47] Kennedy, L. (1991). Farm Succession in Modern Ireland: Elements of a Theory of Succession. The Economic History Review 44(3): 477-499. DOI: 10.1111/j.14680289.1991.tb01275.x.

[48] Kearns, K. (1996). Dublin Pub Life and Lore: An Oral History. Dublin: Gill \& Macmillan.

[49] Kenny, V. (1985). The Post-colonial Mind. The Crane Beag 9(1): 70-78.

[50] Kerblay, B. (1971). Chayanov and the Theory of Peasant Economies (pp. 176-184). In Shanin, T., ed., Peasant and Peasant Societies. London: Penguin Books.

[51] Kirbak, L \& Egil-Flø, B. (2005). Joint farming - between Good Agronomy and Modern Masculinity (pp. 1-17). In Conference paper to the XXI Congress of the European Society for Rural Sociology, Keszthely.

[52] Kirby, P., Gibbons, L. \& Cronin, M. (2002). Reinventing Ireland: Culture, Society and the Global Economy. London: Pluto Press.

[53] Kirby, P. (2005). In the wake of the tiger: Mapping Anew the Social Terrain. The Irish review 33(1): 40-50.

[54] Knapp, M., Hall, J. \& Horgan, T. (2014). Nonverbal communication in human interaction. Boston: Wadsworth, Cengage Learning.

[55] Kuhling, C. \& Keohane, K. (2007). Cosmopolitan Ireland: Globalisation and Quality of Life. London: Pluto Books.

[56] Lafferty, S., Commins, P. \& Walsh, J. A. (1999). Irish Agriculture in Transition; a Census Atlas of Agriculture in the Republic of Ireland. Dublin: Teagasc.

[57] Levin, M. D. (1988). Accountability and Legitimacy in Traditional Co-operation (pp. 330-344). In Shanin, T., ed., Peasant and Peasant Societies. London: Penguin Books.

[58] Macken-Walsh, A. (2009). Barriers to Change: A Sociological Study of Rural Development in Ireland. Galway: Teagasc Rural Economy Research Centre.

[59] Macken Walsh, A. (2010). A Review of the Social Benefits of Joint Farm Ventures. Teagasc Working Paper Series.

[60] Macken-Walsh, A. \& Brosnan, K. (2012). The Potential of an Enhanced Cooperation Measure in the EAFRD (2014-2020): the case of Ireland. Dublin: Department of Agriculture, Food and the Marine.

[61] Macken-Walsh, A. \& Roche, B. (2012). Facilitating Farmers' Establishment of Farm Partnerships: A Participatory Template. Carlow: Teagasc.

[62] Macken-Walsh, A. \& Byrne, A. (2014). Strategies of Resilience: Cooperation in Irish family Farming. Proceeding from Year of the Family Farm Conference 2014: Dublin.

[63] Macken-Walsh, A. \& Byrne, A. (2015). Cooperation in Irish Family Farming. In Meredith, D., ed., Family Farming in Ireland: Continuity and Change. Dublin: Royal Irish Academy.

[64] Macken-Walsh, A. Heanue, K, Meredith, D., Byrne, A., Cush, P. \& Rush, P. (2015). Joint Ventures to Enhance the Demographic Profile and Socio-Economic Sustainability of Irish Farming (Join to Farm). Presentation to Join-to-farm Stakeholder Group, Teagasc, Athenry.

[65] Matthews, A. (2013). Family Farming and the role of policy in the EU. Retrieved from: http://capreform.eu/family-farming-and-the-role-of-policy-in-the-eu/.

[66] McDonald, R., Macken-Walsh, A., Pierce, K., \& Horan, B. (2014). Farmers' Responses to a Deregulated Dairy Regime: insights from Ireland's New Entrants Scheme. Land Use Policy, 41: 21-30, DOI: 10.1016/j.landusepol.2014.04.018.

[67] McGoldrick, M. (1982). Irish Families (pp. 310-339). In McGoldrick, M., Pearce J. \& Giordano, J., eds., Ethnicity and Family Therapy. New York: The Guildford Press. 
[68] Moane, G. (2002). Legacies of history and the Quest for Vision: Colonialism and the Celtic Tiger (pp. 109-123). In Kirby, P. Gibbons L. \& Cronin M., eds., Reinventing Ireland. London: Pluto Press.

[69] Moane, G. (2014). Postcolonial legacies and the Irish psyche (pp. 121-132). In Inglis, T., ed., Are the Irish Different Manchester: Manchester University Press.

[70] Nass, C. \& Yen, C. (2010). The Man Who Lied to His Laptop: What We Can Learn About Ourselves from Our Machines. New York: Penguin.

[71] Ní Laoire, C. (2005). You're not a man at all! Masculinity, Responsibility and Staying on the Land in Contemporary Ireland. Irish Journal of Sociology 14(2): 94-104. DOI: $10.1177 / 079160350501400206$.

[72] Ngo, M. \& Brklacich, M. (2014). New farmers' efforts to create a sense of place in rural communities: insights from southern Ontario, Canada. Agriculture and Human Values 31(1): 53-67. DOI: 10.1007/s10460-013-9447-5.

[73] O'Dowd, A. (1979). MEITHEAL: A Study of Co-operative Labour in Rural Ireland. Dublin: The Leinster Leader.

[74] Oldenburg, R. (1999). The Great Good Place: cafes, coffee shops, bookstores, bars, hair salons and other hangouts at the heart of a community. Boston: Da Capo Press.

[75] Ostrom, E. (1991). Rational Choice Theory and Institutional Analysis: Toward Complementarity. American Political Science Review, 85(1): 237-43. DOI: 10.2307/1962888.

[76] Ostrom, E. (1998). A behavioural Approach to the Rational Choice Theory of Collective Action. American Political Science Review, 92(1): 1-22. DOI: 10.2307/2585925.

[77] Ostrom, E., Gardner, R. \& Walker. J. (1994). Rules, Games, and Common Pool Resources. Ann Arbor, Michigan: University of Michigan Press.

[78] Ostrom, E. (2010). Analysing Collective Action. Agricultural Economics, 41(1): 155-166. DOI: 10.1111/j.1574-0862.2010.00497.x.

[79] Phyne, J. (1999). Rural Social Change and Conflicts Associated with the Irish Salmon Farming Industry, 1987-1995. Farnham: Ashgate.

[80] Popkin, S. (1979). The Rational Peasant: The Political Economy of Rural Society in Vietnam. Berkeley: University of California Press.

[81] Putnam, D. (2000). Bowling Alone: The Collapse and Revival of the American Community. New York: Simon and Schuster Paperbacks.

[82] Roszenweig, R. (1991). The rise of the Saloon (pp. 121-156). In Mukerji, C. \& Schudson, M., eds., Rethinking Popular Culture: Contemporary Perspectives in Cultural Studies. Los Angeles: University of California Press.

[83] Ruddy, M. \& Varley, T. (1991). Sea farming and Development in North Connemara (pp. 77102). In Varley, T. Boylan, T. \& Cuddy, M. P., eds., Rural Crises: Perspectives on Irish Rural Development. Galway: Galway Centre for Development Studies.

[84] Share, P. (2003). A Genuine 'Third Place'? Towards an understanding of the pub in contemporary Irish Culture. Cavan, Ireland, conference proceedings from the $30^{\text {th }}$ Sociological Association of Ireland Conference.

[85] Shortall, S. (1997). Women, farming and access to land. Irish Journal of Sociology, 7: 111- 118. DOI: $10.1177 / 079160359700700107$.

[86] Shortall, S. \& Byrne, A. (2009). Gender and Sustainability in Rural Ireland (pp. 287-302). In McDonagh, J., Varley, T. \& Shortall, S., eds., A Living Countryside: The Politics of Sustainable Development in Rural Ireland. Burlington: Ashgate Publications.

[87] Shortall, S. (2014). Farming, identity and well-being: managing changing gender roles within Western European farm families. Anthropological Notebooks 20(3): 67-81. 
[88] Stone, T. \& Postdam, S. (1996). Creating moral economies: reciprocity and welfare entitlements on the Yukon mining frontier. Journal of Socio Economics 25(5): 537-558. DOI: 10.1016/S1053-5357(96)90016-5.

[89] Sutherland, L. A. \& Burton, R. J. F (2011). Good Farmers, Good Neighbours? The Role of Cultural Capital in Social Capital Development in a Scottish Farming Community. Sociologia Ruralis 51(3): pp. 238-255. DOI: 10.1111/j.1467-9523.2011.00536.x.

[90] Taylor, L. (1987). The River Would Run Red with Blood: Community and Common Property in an Irish Fishing Settlement (pp. 290-307). In: McCay, B. \& Acheson, J., eds., The Question of the Commons: The Culture and Ecology of Communal Resources. Tucson: University of Arizona Press.

[91] Teagasc (2016a). Specimen on Farm Agreement: Farm Partnerships. Available at: http://www.teagasc.ie/collaborativearrangements/farm_partnership/info_forms.asp. Retrieved 23/02/2016.

[92] Teagasc (2016b). Specimen Share Farming Agreement. Available at: http://www.teagasc.ie/collaborativearrangements/share_farming/SharefarmingAgreementW ithNotesFinal150210.pdf. Retrieved 23/02/2016.

[93] Teagasc (2016c). Specimen Agreements for the Contract Rearing of Replacmenet Heifers. Available at: http://www.teagasc.ie/collaborativearrangements/specimen agreements.asp. Retrieved 23/02/2016.

[94] Turner, M \& Hambly, J. (2005) Agricultural restructuring: The potential role of joint venture arrangements, University of Exeter, Centre for Rural Research, Annual Review 2004: Available online:

http://centres.exeter.ac.uk/crpr/publications/pdfs/annualreview/AnnualReview04.pdf.

[95] Varley, T. \& Cearbhaill, D. O. (2002). Towards a Theory of State-Community Partnerships: Interpreting the Irish Muintir Na Tíre Experience. Journal of the Community Development Society, 33(1): 53-70. DOI: 10.1080/15575330209490142.

[96] Varley, T. \& Curtin, C. (2006). The Politics of Empowerment: Power, Populism and Partnership in Rural Ireland. The Economic and Social Review 37(3): 423-446.

[97] Whatmore, S., Lowe, P. \&. Marsden, T., eds., Rural Enterprises Shifting Perspectives on Small-Scale Production, Food Harvest 2020 - A vision for Irish Agri-food and fisheries. Dublin: Department of Agriculture, Fisheries and Food.

[98] Wolf, E. R. (1966). Peasants. Prentice Hall: Eaglewood Cliffs.

[99] Woods, M. (2014). Family farming in the global countryside. Anthropological Notebooks 20(3): 31-48. 